\section{Regeneration In Vitro From the Hypocotyl of Cucumis Species Produces Almost Exclusively Diploid Shoots, and Does Not Require Light}

\author{
Sebahattin Curuk ${ }^{1}$ \\ Department of Virology, ARO Volcani Center, POB 6, Bet Dagan 50250, Israel; \\ Laboratory of Plant Biotechnology, University of Cukorova, Adana, Turkey
}

G. Ananthakrishnan ${ }^{2}$, Sima Singer, Xiaodi Xia, and Chassia Elman

Department of Virology, ARO Volcani Center, POB 6, Bet Dagan 50250, Israel

\section{David Nestel \\ Department of Entomology, ARO Volcani Center, POB 6, Bet Dagan 50250, Israel}

\section{Selim Cetiner ${ }^{3}$ \\ Laboratory of Plant Biotechnology, University of Cukorova, Adana, Turkey}

Victor Gaba ${ }^{4}$

Department of Virology, ARO Volcani Center, POB 6, Bet Dagan 50250, Israel

Additional index words. melon, cucumber, tetraploid, cotyledon, photocontrol

\begin{abstract}
Hypocotyl explants of three cultivars of melon (Cucumis melo L.) (cvs. Revigal, Topmark and Kirkagac), and a cucumber (C. sativus L. cv. Taoz) rapidly directly regenerated multiple shoots on Murashige and Skoog medium augmented with $4.4 \mu \mathrm{M}$ benzyladenine. Regeneration from the hypocotyl resulted in nearly $100 \%$ diploid shoots, whereas regeneration from the cotyledons resulted in $40 \%$ to $70 \%$ polyploid regenerants. Regeneration from cotyledon explants of melon cv. Revigal required light, whereas regeneration from hypocotyl explants of melon cv. Revigal occurred in both light and darkness. Direct regeneration also occurred from the hypocotyl of cucumber cv. Taoz in both light and darkness, even though cotyledonary explants did not regenerate buds or shoots under the same conditions. This is the first report of regeneration from the Cucumis genus producing a fully diploid plant population.
\end{abstract}

Somaclonal variation, the production of regenerants or transformants that are not trueto-type, is a major problem of plant tissue culture and transformation. Production of polyploid (usually tetraploid) plants is common type of somaclonal variation. Regen-

Received for publication 13 Nov. 2001. Accepted for publication 8 May 2002. Contribution from the Agricultural Research Organization, The Volcani Center, Bet Dagan, Israel, No. 528/01. This work was supported by a Research grant to V.G. from the Chief Scientist of the Ministry of Agriculture (Israel), and to S. Curuk from the Scientific and Technical Research Council of Turkey (TUBITAK/BAYG). G.A. was supported by the MASHAV program of the Ministry of Foreign Affairs, Israel. We thank B. Steinitz, A. Zelcer and J.D. Klein for critical comments.

${ }^{1}$ Current address: Univ. of Mustafa Kemal, Faculty of Agriculture, Dept. of Horticulture, 31034 AntakyaHATAY, Turkey.

${ }^{2}$ Current address: Citrus Research and Education Center, Univ. of Florida, 700 Experiment Station Rd., Lake Alfred, FL 33850, USA.

${ }^{3}$ Current address: Sabanci Univ., Faculty of Engineering and Natural Sciences, 81474 Tuzla, Istanbul, Turkey.

${ }^{4}$ To whom reprint requests should be addressed. Telephone: 972-3-9683769; fax: 972-3-9604180; email:vpgaba@volcani.agri.gov.il eration of Cucumis species in vitro produces a large proportion, often greater than $30 \%$, of tetraploid plants in melon $(C$. melo) (Ezura et al., 1992; Guis et al., 2000), cucumber (C. sativus) (Colijn-Hooymans et al., 1994) and the African horned cucumber (C.metuliferus $\mathrm{E}$. of plants produced in a melon genetic transformation program is often tetraploid (Ayub et al., 1996; Grumet et al., 1995; Guis et al., 2000), and are a great waste of resources.

We recently found that melon hypocotyl explants rapidly regenerate multiple shoots, but only when attached to a fragment of cotyledon (Curuk et al., 2002). Rapid direct shoot regeneration from the proximal end of the hypocotyl followed a distinct morphological sequence (Curuk et al., 2002), compared to a discrete slower morphogenic pathway for direct regeneration from excised melon cotyledons (Gaba et al., 1999). Previously, melon and cucumber were thought not to possess the ability to regenerate through direct organogenesis from the hypocotyl (Wehner and Locy, 1981). Nevertheless, callus derived from hypocotyl explants of melon and cucumber can regenerate shoots (Boubdallah and Branchard, 1986; Kim et al., 1988). Variations in regeneration Mey. ex Naud.) (Adelberg, 1998). The majority technique may alter the rate of production of tetraploids in tissue culture of melon and other Cucumis species (Adelberg, 1998; Adelberg et al., 1994; Guis et al., 2000). Consequently, in our studies of a new regeneration pathway from the melon hypocotyl, we tested our new regenerant populations for ploidy, and we report for the first time regeneration of near $100 \%$ diploid populations from the genus Cucumis.

Additionally, we determined the light requirement for regeneration from hypocotyl and cotyledon explants, as light is known to affect in vitro morphogenesis (Lercari et al., 1986), and show that photocontrol of regeneration responses differ between cotyledon and hypocotyl explants.

\section{Materials and Methods}

Seed germination. Melon seeds (Cucumis melo L.) of cultivars Revigal (an Israeli 'Galia' type) (Hazera Seeds, Israel) and Topmark (a U.S. Western Shipper cantaloupe type) (Asgrow Seed Co., Kalamazoo, Mich.) with seed coats removed, were surface sterilized for $20 \mathrm{~min}$ in $1 \%$ sodium hypochlorite, with two drops of Tween 20 (polyoxyethylenesorbitan) per $100 \mathrm{~mL}$. After washing with sterile distilled water, seeds germinated on Murashige and Skoog (1962) (MS) medium with $3 \%$ sucrose, MS vitamins and $8 \mathrm{~g} \cdot \mathrm{L}^{-1}$ Agar (Sigma A1296) (MS0 medium), in $90 \times$ $15 \mathrm{~mm}$ petri dishes ( $25 \mathrm{~mL}$ medium perdish), in a growth room at $25 \pm 1{ }^{\circ} \mathrm{C}, 16$-h photoperiod, $30-40 \mu \mathrm{mol} \cdot \mathrm{m}^{-2} \cdot \mathrm{s}^{-1}$ cool-white fluorescent light. These growth conditions were used for all experiments, except where noted. Seeds of the Turkish inodorus winter melon type cultivar Kirkagac 637 (Cagdas Seed Co., Turkey) with seed coats removed, were sterilized for $5 \mathrm{~min}$ in $70 \%$ ethanol, washed with three times sterile distilled water and $45 \mathrm{~min}$. in $1 \%$ sodium hypochlorite, with Tween 20 as above. Seeds were washed three times with sterile distilled water, then for $15 \mathrm{~min}$. in $500 \mathrm{mg} \cdot \mathrm{L}^{-1}$ each carbenicllin and claforan, and germinated on MSO medium, in a growth room at $28 \pm 1{ }^{\circ} \mathrm{C}, 16-\mathrm{h}$ photoperiod, $100-120 \mu \mathrm{mol} \cdot \mathrm{m}^{-2} \cdot \mathrm{s}^{-1} \mathrm{cool}-$ white fluorescent light. All the work with 'Kirkagac' was performed in these growth conditions. Cucumber (Cucumis sativus L.) seeds of the gynoecious parthenocarpic hybrid Bet Alpha type cv. Taoz (HA-1296) (Hazera Seed Co., Israel) were sterilized with troclosene sodium (Medentech, Wexford, Eire) $\left(0.85 \mathrm{~g} \cdot \mathrm{L}^{-1}\right.$ a.i. for $10 \mathrm{~min}$ ), washed four times with sterile distilled water, and germinated on MS0 medium in petri dishes.

Explant preparation. Hypocotyl explants for all cultivars were cut from 4-d-old seedlings as follows: the hypocotyl was cut off close to the cotyledon, then the cotyledon cut across in half, discarding the distal parts. Next the explant was stood on its hypocotyl stub, and a scalpel blade forced flat between the cotyledon remnants. The proximal parts of the cotyledons were then cut apart, each with a fragment of hypocotyl attached. The apical bud of the seedling was excised, using a stereomicroscope, giving a unit $\approx 2.5 \times 3.5 \mathrm{~mm}$ (Curuk et al., 2002). Regeneration proceeded on MS0 
medium with $4.4 \mu \mathrm{M} \mathrm{N}^{6}$-benzyladenine (BA) (MSBA1 medium), in petri dishes. Cotyledon explants were cut from 4-day-old seedlings, removing the part of the cotyledon adjacent to the apex and placed in petri dishes, with the abaxial side on MSBA1 medium (Gaba et al., 1996), [except 'Kirkagac' on the regeneration medium of Neidz et al.(1989)]. After 28-30 d, explant responses were scored.

Shoot elongation. Regenerating areas of hypocotyl or cotyledon explants (or regenerative callus with buds or shoots for 'Taoz') were excised after 4 weeks in culture and transferred to $150 \times 25 \mathrm{~mm}$ tubes with $10 \mathrm{~mL}$ of elongation medium (MS0 medium with $0.44 \mu \mathrm{M} \mathrm{BA}$ and $2.9 \mu \mathrm{M}$ gibberellic acid), for cultivars Revigal and Taoz. For 'Topmark' and 'Kirkagac' the elongation medium of Moreno et al. (1985) [MS0 medium with $0.44 \mu \mathrm{M}$ BA and $0.05 \mu \mathrm{M}$ $\alpha$-naphthaleneacetic acid (NAA)] was used.

Rooting. After 3-4 weeks on elongation medium, 'Revigal', 'Kirkagac' and 'Taoz' shoots were excised ('Revigal' required a minimum shoot length of 10-15 $\mathrm{mm}$ ) and transferred to MS0 medium for rooting and further growth. Some 'Taoz' explants were maintained on elongation medium for a second round of regeneration after shoot removal. 'Taoz' shoots from the second round were excised and rooted. After several transfers each of 3-4 weeks on Moreno et al. (1985) elongation medium, 'Topmark' shoots of 10-15 mm length were excised and transferred to MS0 medium with $0.05 \mu \mathrm{M}$ NAA (Chee, 1991) for rooting.

Development in darkness. Petri dishes containing hypocotyl or cotyledon explants of melon 'Revigal' or cucumber 'Taoz' were wrapped in two layers of aluminum foil, and placed on the same shelf in the growth room as those plates containing explants exposed to the standard environment, on MSBA1 medium. Explants of the proximal half of the cotyledon, after removal of the area adjacent to the seedling apex, were used in these experiments, treated as above. Samples were observed weekly by stereomicroscope. Regeneration was scored after 4 weeks.

Flow cytometry. Flow cytometry was used for the analysis of ploidy. In vitro-grown leaves of melon and cucumber from rooted plants were chopped with a razor blade into an ice-cold neutral buffer (De Laat and Blaas, 1984), stained with DAPI, filtered through a $40-\mu \mathrm{m}$ mesh, and the fluorescence of the nuclei measured with a PAS II Flowcytometer (Partec GmbH, Munster, Germany). Analyses were performed by Plant Cytometry Services, Schijndel, The Netherlands.

Statistics. Results were analysed using a Chi-square test under the hypothesis of no association (Sokal and Rohlf, 1981), with Yates' correction when required. There were 5-6 explants per petri dish, 5-10 petri dishes per treatment, with 2-4 repeats of each experiment.

\section{Results and Discussion}

Ploidy of regenerants. Regeneration from both hypocotyl (Curuk et al., 2002) and cotyledons (Gaba et al., 1999) of melon was by direct organogenesis. Regeneration from the hypocotyl resulted in $100 \%$ diploid regenerated shoots from 'Kirkagac' and 'Revigal', and those from 'Topmark' were $96 \%$ diploid (Fig. 1). Overall, 99\% of the regenerants from the hypocotyl explants were diploid (Fig. 1). However, regeneration from the cotyledons of the three melon cultivars resulted in $43 \%$ one of the polyploid plants were tetraploid, the exception being an octaploid plant of 'Revigal'. Shoots of different ploidy were recovered from individual cotyledon explants of 'Revigal'. Regenerating 'Topmark' cotyledons (but not hypocotyls) were much afflicted by hyperhydration during the elongation phase, and most were lost. There was no cultivar effect on the ploidy of regenerants from the hypocotyl or cotyledon.

Regenerants from the hypocotyl of cucumber 'Taoz' were 100\% diploid (32 regenerants in all), whether regenerated from tissue incubated in darkness $(n=9)$ or light (for one or two regenerative cycles) $(n=20)$, or from callus derived from hypocotyl explants $(n=3)$. There was no effect of light on ploidy of regenerants from the hypocotyl of cucumber.

This is the first report of highly diploid regenerated populations in the genus $\mathrm{Cucu}$ mis. Regeneration of mixed diploid/polyploid populations of Cucumis is noted from a variety of explants, and by a variety of regeneration pathways, as first noted by Ezura et al. (1992). Expanding on the analysis of Ezura et al. (1992), tetraploid melon plants are regenerated from cotyledons (Adelberg et al., 1993, 1994; Ezura et al., 1992; Gius et al., 2000), leaves (Yadav et al., 1996; Gius et al., 2000), and callus derived from hypocotyl, cotyledon or leaves (Boubdallah and Branchard, 1986; Moreno and Roig, 1990). In these reports, the percentage of polyploid melon plants regenerated was $30 \%$ to $80 \%$, whether by somatic embyogenesis (Ezura et al., 1992; Gius et al., to $70 \%$ polyploid regenerants (Fig. 1). All but

2000), direct organogenesis (Adelberg et al., 1993, 1994; Ezura et al., 1992; Yadav et al., 1996) or regeneration from callus (Moreno and Roig, 1990). Regeneration of tetraploid plants from cucumber callus (Kim et al., 1988) and directly from cucumber cotyledons (Colijn-Hooymans et al., 1994) is reported. Tetraploid plants are regenerated at similar frequencies in other species, such as tomato (Lycoperscion esculemtum Mill.) (Compton and Veilleux, 1991) and Arabidopsis (Morris and Altmann, 1994).

The production of tetraploid plants is due to endo-reduplication in the cells of the explant prior to regeneration; polyploid plants regenerate from polyploid cells in the explant (ColijnHooymans et al., 1994; Adelberg et al., 1994; Adelberg, 1998). Polysomaty, different tissues/ organs having different ploidy levels due to differences in age and rates of development, occurs throughout cucumber and Arabidopsis plants, the level of ploidy increasing with organ age (Colijn-Hooymans et al., 1994; Galbraith et al., 1991; Gilissen et al., 1993). Polysomaty is already present in cucumber seed (Gilissen et al., 1993). Changes in the ploidy level of the explant due to maturity or aging (Adelberg et al., 1994; Colijn-Hooymans et al., 1994; Guis et al., 2000) are seen in the composition of the regenerant population. Recently Guis et al. (2000) found that only $15 \%$ of plants regenerating by organogenesis from melon leaf explants are tetraploid, demonstrating again that source tissue is an important determinant of ploidy of regenerants. Regeneration of a tomato population with only $3 \%$ tetraploids was reported by Pozueta-Romero et al. (2001), using seedling explants consisting of a cotyledon and a shoot, with the apex and other cotyledon removed. The 'flamingo bill' explants of Pozueta-Romero et al. (2001) regenerated shoots directly and rapidly from the top of the hypocotyl as reported here, with histology similar to that of Curuk et al. (2002). The population of young, rapidly dividing cells in the proximal

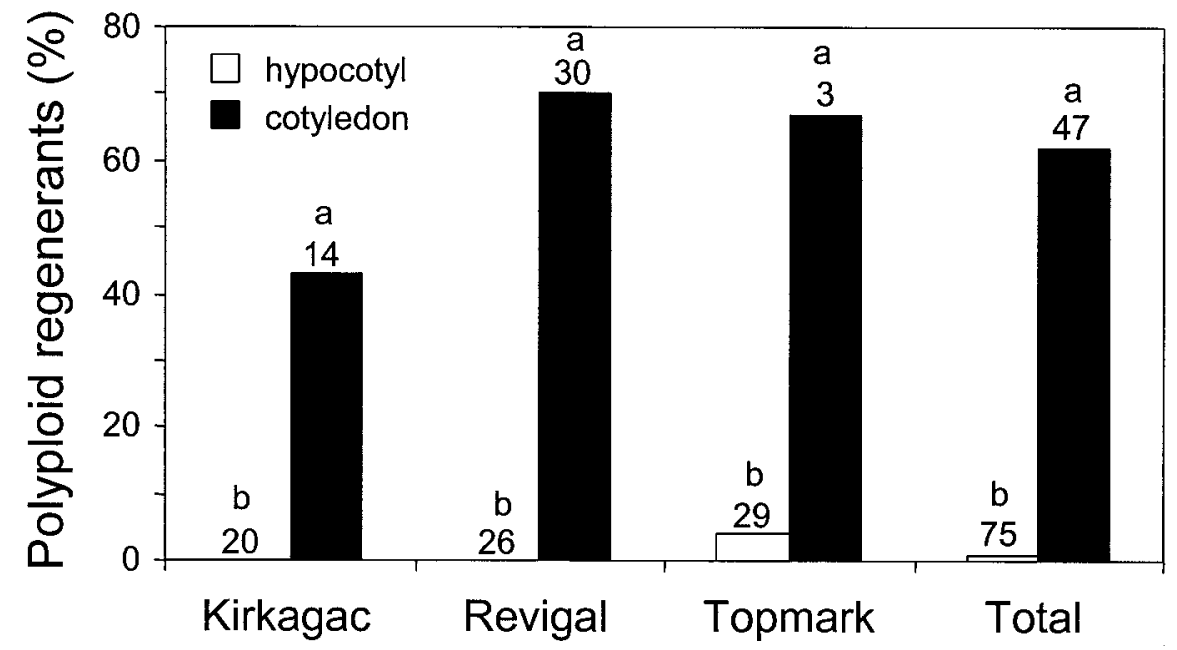

Fig 1. Polyploidy of hypocotyl and cotyledon regenerants of melon. Melon plants were regenerated from both hypocotyl and cotyledon explants of cvs. Kirkagac, Revigal, and Topmark cultured in the light. The polyploid regenerants are expressed as percentage of the population. The number on each column is the number of individual plants in that sample. The effect of source explant on the proportion of polyploid regenerants recovered for each cultivar (and together) was separated by Chi-square tests at $P<0.01$, those affected in a statistically significant manner being marked by different letters. 

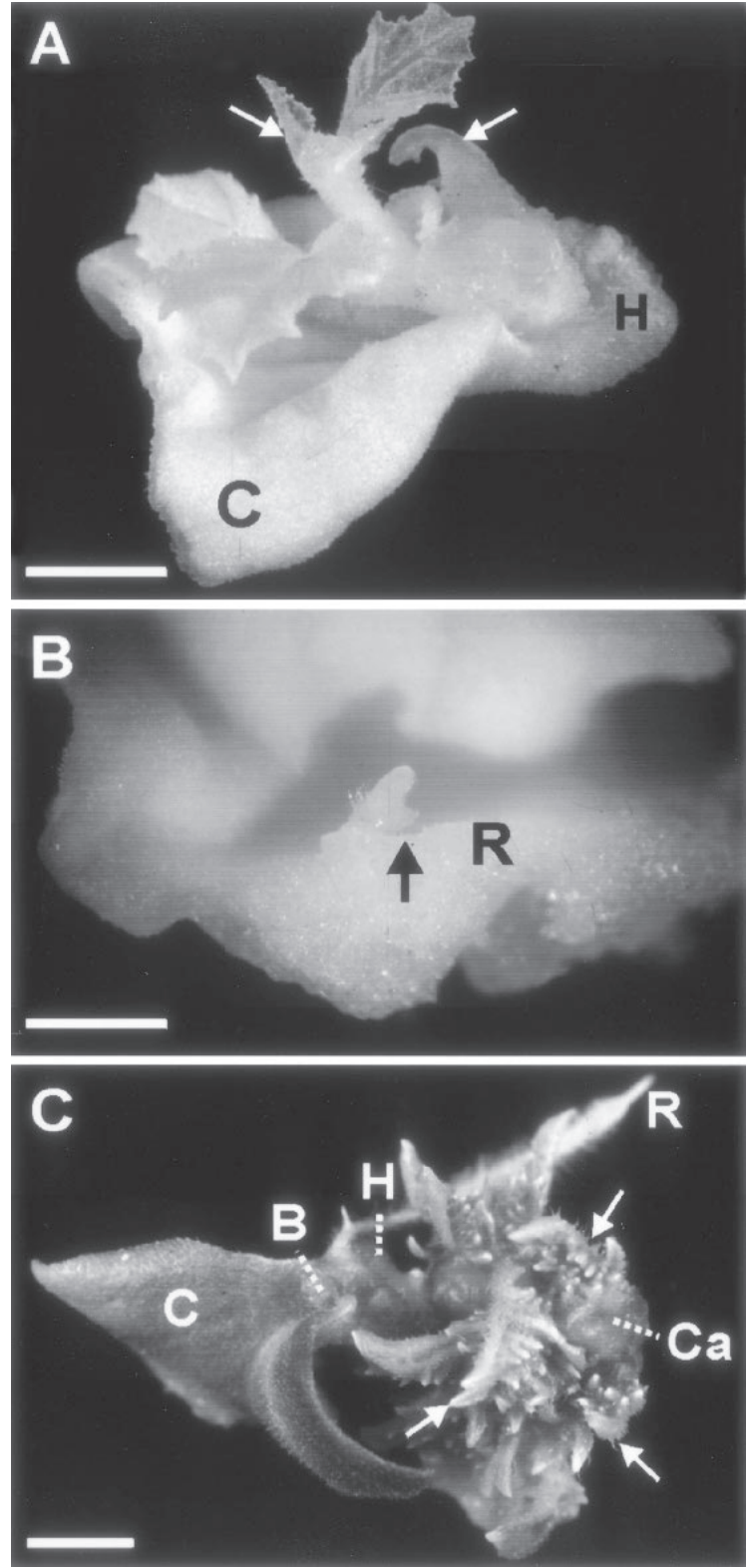

Fig. 2. Regenerating explants of Cucumis in light and darkness. (A) A well-developed melon 'Revigal' hypocotyl explant, after $21 \mathrm{~d}$ in darkness. Arrows mark the shoots. The cotyledon fragment (C) and the hypocotyl stump $(\mathrm{H})$ are labeled $(\mathrm{bar}=2.5 \mathrm{~mm})$. $(\mathbf{B})$ Close-up of the proximal edge of a 'Revigal' proximal cotyledon explant maintained in darkness for $30 \mathrm{~d}$. A small number of explants regenerate a single protuberance (arrow), on the proximal ridge $(\mathrm{R})(\mathrm{bar}=0.5 \mathrm{~mm}) .(\mathrm{C})$ Regeneration from a cucumber 'Taoz' hypocotyl in the light. A well-developed hard green callus (Ca) has grown from the hypocotyl $(\mathrm{H})$. Buds and shoots are visible regenerating from the callus (arrows). A regenerating bud (B) is also visible on the hypocotyl near the base of the cotyledon (C). A root (R) has also developed; (bar $=5 \mathrm{~mm}$ ). It is unusual for a single explant to display all these phenomena.

region of the hypocotyl regenerated new shoots very rapidly (Curuk et al., 2002). The diploid nature of the cells derived from the proximal region of the hypocotyl was maintained for $3-4$ months in culture in our work here, without the massive endoreduplication found in other vegetative Cucumis tissues (Colijn-Hooymans et al., 1994; Gilissen et al., 1993), and these cells thus produce almost exclusively diploid plants. Similarly, in Arabidopsis, the mature plant organs were multiploid, while the somatic floral tissues were maintained diploid (Galbraith et al., 1991). There are therefore mechanisms to maintain the diploid state of cer- tain plant tissues. Afew of the regenerants from hypocotyl explants here were slightly chimeric with tetraploid cells (with a single tetraploid regenerant), suggesting either that cells from the cotyledon were eventually recruited into the regeneration process from the hypocotyl, or that there was limited endoreduplication in the hypocotyl-derived regenerating tissues.

Melon-regeneration from hypocotyl explants in darkness. After 1 week in darkness, the cotyledon part of the explant was still yellow, and the most proximal end of the cotyledon and the hypocotyl were still white. The hypocotyl stump swelled massively, and there was a single well-developed protuberance near the junction of the cotyledon and the hypocotyl. A single small shoot was visible after 2 weeks in darkness. After 3 weeks in darkness, in many samples there were several shoots growing (Fig. 2A). Nearly $90 \%$ of explants regenerated shoots after 4 weeks in darkness (Fig. 3). The proportion of hypocotyl explants regenerating after 4 weeks in light was similar (Fig. 3). There was no effect of light on production of shoots from hypocotyl explants (Fig. 3).

Melon-regeneration from cotyledon explants in darkness. The development of regeneration from the hypocotyl in darkness contrasted strongly with the development of the regenerating part of cotyledon explants. The morphology and anatomy of the development of regeneration of proximal cotyledon explants of Cucumis melo L. cv. Galia on the same medium (MSBA1) in the light has been previously described by Gaba et al. (1999). In contrast, development was greatly slowed in darkness. After 1 week in culture, the proximal cotyledon explant was yellow. A white ridge developed at the proximal edge of the explant. In light-grown samples this ridge was yellow (Gaba et al., 1999). After 2 weeks in culture, the explant enlarged and swelled notably on the proximal part, with no sign of the prolific development found in light-grown cotyledon samples (Gaba et al., 1999). After a month in culture there was little further development, and the explants were gently rippled, without features of regeneration. However, $11 \%$ of cotyledon proximal explants developed a leaf or single protuberance (probably a leaf primordium - see Gaba et al., 1999) in darkness (Fig. 2B), usually adjacent to the most proximal edge (Fig. 3). Illumination strongly enhanced primordium/leaf production from the cotyledons (Fig. 3). No shoots regenerated from cotyledon explants in darkness (Fig. 3). Regeneration from cotyledon sections in the light was at a similar level to that in hypocotyl sections. However, as noted previously (Gaba et al., 1999), the regeneration from cotyledons after 4 weeks was only of protuberances and leaves, and there were no visible shoots (Fig. 3).

Regeneration from cucumber. Development of regeneration from the cucumber 'Taoz' hypocotyl explants in light was slower than with melon 'Revigal' (Curuk et al., 2002), protuberances first being observed after $6 \mathrm{~d}$ in culture on MSBA1 medium, $60 \%$ of explants having protuberances after $8 \mathrm{~d}$, and 95\% having protuberances, leaves or shoots after $10 \mathrm{~d}$. Cotyledon or hypocotyl segments (not including the regenerative area from the proximal region of the hypocotyl demonstrated here) of cucumber 'Taoz' did not regenerate directly shoots, buds, or primordia in light or darkness (data not shown). Callus was regenerated frequently from cotyledon segments $(67 \%)$, but infrequently from hypocotyl segments (16\%). Callus from cotyledon segments was rarely regenerative, and only in the light (2/149 explants).

In contrast, hypocotyl explants with a cotyledon fragment attached were very regenerative 


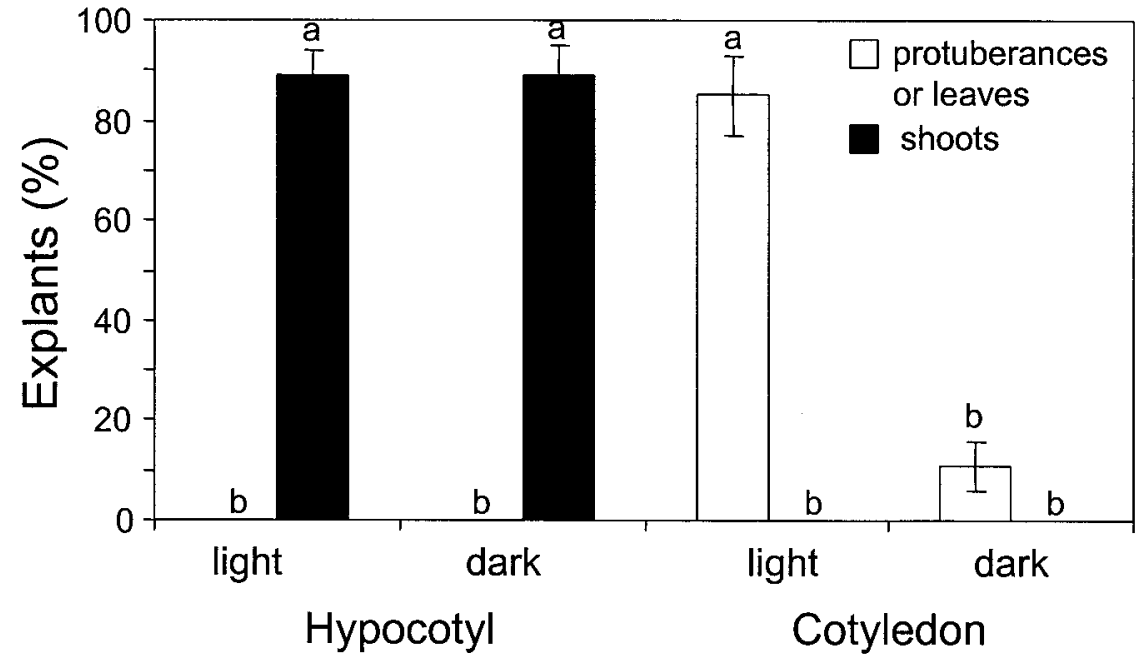

Fig. 3. Regeneration after 4 weeks in light or darkness from hypocotyl and cotyledon explants of 'Revigal' melon. Mean of 3 experiments with 20-40 explants per treatment \pm SD. Explants were scored for the presence of shoots, leaves or protuberances. The effect of light/dark on morphogenesis for each type of explant was separated by Chi-square tests at $P<0.01$, those affected by light/dark in a statistically significant manner being marked by different letters.

(Figs. 2C and 4). Direct regeneration occurred at a high level in both light and darkness (Fig. 4). There was no environmental effect (light/ dark) on regeneration of shoots from hypocotyl explants. However, regeneration of roots from the hypocotyl explant was photocontrolled (Figs. 2C and 4), as was the production of green regenerable callus (Fig. 4), sometimes bearing buds or shoots after the first period in culture (Fig. 2C).

Regeneration from hypocotyl explants of 'Revigal' melon and 'Taoz' cucumber in darkness was a novel response in cucurbits, and the differential photoresponse of the organs is unusual. Cotyledon explants of both melon (Leshem et al., 1995; Neidz et al., 1989) and cucumber (Gambley and Dodd, 1991) require light for regeneration, as demonstrated here, in the only other studies of the organogenic response to light of Cucumis explants in vitro.
However, production of axillary shoots induced by cytokinin from the area around the shoot apex in cucumber is not light dependant (Gambley and Dodd, 1991). Dark pretreatments to the seedlings from which the explants were taken stimulate subsequent light-dependant organogenesis in watermelon (Compton, 1999). Light is required for the regeneration of some species, whereas others do not require light, or light may even be inhibitory to regeneration (Lercari et al., 1986).

We demonstrated here novel physiological attributes of a new direct regeneration pathway in Cucumis. The hypocotyl regeneration response was found in three melon genotypes as well as cucumber. The hypocotyl regeneration pathway, widespread in Cucumis, is of interest for biotechnology, as it can potentially avoid the production of tetraploid transformants in melon.

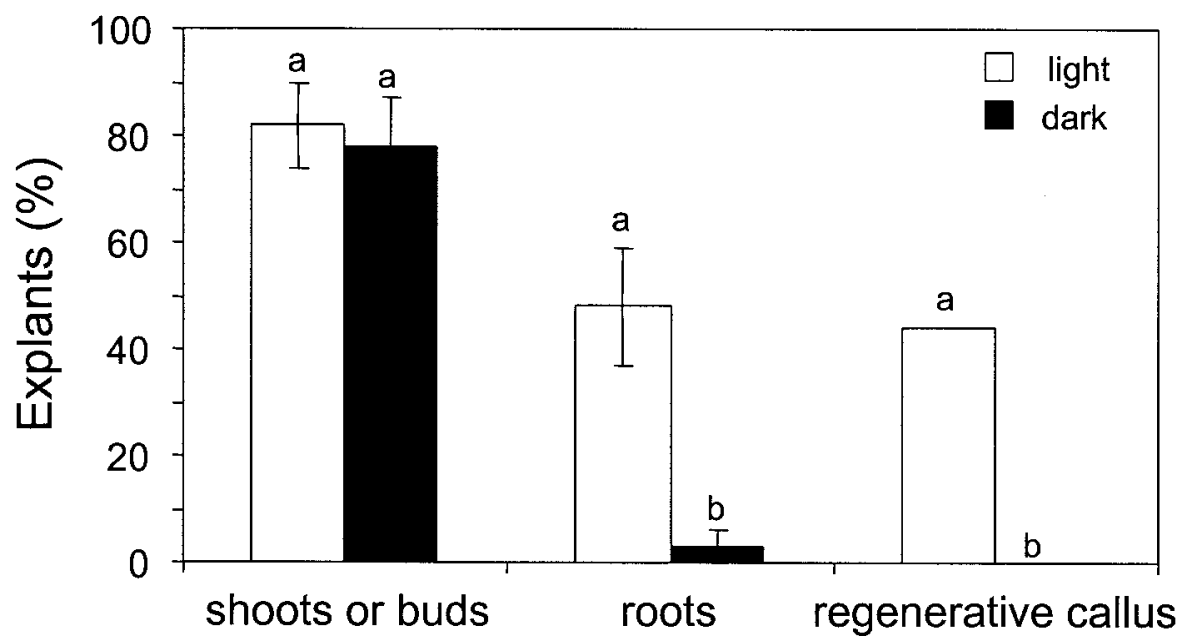

Fig. 4. Regeneration from hypocotyl explants of cucumber 'Taoz' in light or darkness. Explants were scored for the production of shoots or buds, roots, or green regenerative callus. Average of two separate experiments of regeneration from hypocotyl. Results are mean \pm SD. Total explants: $30-44$ per treatment. The effect of light/dark on each type of morphogenesis was separated by Chi-square tests at $P<0.01$, those affected by light/dark in a statistically significant manner being marked by different letters.

\section{Literature Cited}

Adelberg, J. 1998. Regeneration and frequency of tetraploid variants of Cucumis metuliferus are affected by explant induction on semi-solid medium versus the liquid/membrane system. Plant Cell Rpt. 17:225-229.

Adelberg, J., B. Rhodes, and H. Skorupska. 1993. Generating tetraploid melon in tissue culture. Acta Hort. 336:373-380.

Adelberg, J., B. Rhodes, H. Skorupska, and W. Bridges. 1994. Explant origin affects the frequency of tetraploid plants from tissue culture of melon. HortScience 29: 689-692.

Ayub, R., M. Guis, M. Ben Amor, L. Gillot, J.P. Roustan, A. Latche, M. Bouzayan, and J.C. Pech. 1996. Expression of ACC oxidase antisense gene inhibits ripening of cantaloupe melon fruits. Nature Biotech. 14:862-866.

Boubdallah, L. and M. Branchard. 1986. Regeneration of plants from callus cultures of Cucumis melo L. Z. Pflanzenzuchtg. 96:82-85.

Chee, P.P. 1991. Plant regeneration from cotyledons of Cucumis melo 'Topmark'. HortScience 26: 908-910.

Colijn-Hooymans, C.M., J.C. Hakkert, J. Jansen, and J.M.B. Custers. 1994. Competence for regeneration of cucumber cotyledons is restricted to specific developmental stages. Plant Cell Tiss. Org. Cult. 39:211-217.

Compton, M.E. 1999. Dark pretreatment improves adventitious shoot organogenesis from cotyledons of diploid watermelon. Plant Cell Tiss. Org. Cult. 58:185-188.

Compton, M.E. and R.E. Veilleux. 1991. Variation for genetic recombination among tomato plants regenerated from three tissue culture systems. Genome 34:810-817.

Curuk, S., C. Elman, E. Schlarman, O. Sagee, I. Shomer, S. Cetiner, D.J. Gray, and V. Gaba. 2002. A novel pathway of rapid shoot regeneration from the proximal zone of the hypocotyl of melon (Cucumis melo L.). In Vitro Cell. Dev. Biol.-Plant. 38:260-267.

De Laat, A.M.M., and J. Blaas. 1984. Flow cytometric characterization and sorting of plant chromosomes. Theoret. Appl. Genet. 67:463-467.

Ezura, H., H. Amagi, K. Yoshioka, and K. Oosawa. 1992. Highly frequent appearance of tetraploidy in regenerated plants, a universal phenomenon in tissue cultured melon (Cucumis melo L.). Plant Sci. 85:209-213.

Gaba,V.,E.Elman, A.A. Watad, and D.J. Gray. 1996. Ancymidol hastens in vitro bud development in melon. HortScience 31:1223-1224.

Gaba, V., E. Schlarman, C. Elman, O. Sagee, A.A. Watad, and D. J. Gray. 1999. In vitro studies on the anatomy and morphology of bud regeneration in melon cotyledons. In Vitro Cell. Dev. Biol.Plant 35:1-7.

Galbraith, D.W., K.R. Harkins, and S. Knapp. 1991 Systemic endopolyploidy in Arabidopsis thaliana. Plant Physiol. 96:985-989.

Gambley, R.L. and W.A. Dodd. 1991. The influence of cotyledons in axillary and adventitious shoot production from the cotyledonary nodes of $\mathrm{Cu}$ cumis sativus L. (cucumber). J Exp. Bot. 42: 1131-1135.

Gilissen, L.J.W., M.J. van Staveren, J.Creemers-Molenaar, and H.A. Verhoeven. 1993. Development of polysomaty in seedlings and plants of Cucumis sativus L. Plant Sci. 91:171-179.

Grumet, R., R.C. Yadav, G. Akula, S. Hammar, and R. Provvidenti. 1995. Genetic engineering of virus resistance in cucurbit crops, p. 17-22. In: G. Lester and J. Dunlap (eds.). Proc. of Cucurbitaceae '94. Gateway Printing, Texas.

Guis, M., M. Ben Amor, A. Latche, J.C. Peche, and J.P. Roustan. 2000. A reliable system for the 
transformation of cantaloupe charentais melon (Cucumis melo L. var. cantalupensis) leading to a majority of diploid regenerants. Scientia Hort. 84:91-99.

Kim,S.G., J.R. Chang,H.C. Cha, and K.W.Lee. 1988. Callus growth and plant regeneration in diverse cultivars of cucumber (Cucumis sativus L.). Plant Cell Tiss. Org. Cult. 12:67-74.

Lercari, B., F. Tognoni, G. Anselmo, and D. Chapel. 1986. Photocontrol of in vitro bud differentiation in Saintpaulia ionantha leaves and Lycopersicon esculentum cotyledons. Physiol Plant. 67 340-344.

Leshem, B., R. Ronen, E. Soudry, S. Lurie, and S. Gepstein. 1995. Cytokinin and white light coact to enhance polypeptide metabolism and shoot regeneration in cultured melon cotyledons. J. Plant Physiol. 145:291-295.
Morris, P.C. and T. Altmann. 1994. Tissue culture and transformation, p. 173-222. In: C.R. Somerville and E.M. Meyerowitz (eds.). Arabidopsis, Cold Spring Harbor Lab. Press.

Murashige, T. and F. Skoog. 1962. A revised medium for rapid growth and bioassays with tobacco tissue cultures. Physiol. Plant. 15:473-497.

Moreno, V., M. Garcia-Sogo, I. Granell, B. GarciaSogo, and L.A. Roig. 1985. Plant regeneration from calli of melon (Cucumis melo L., cv. 'Amarillo Oro'). Plant Cell Tiss. Org. Cult. 5: 139-146.

Moreno, V. and L.A. Roig. 1990. Somaclonal variation in Cucurbits, p. 435-464. In: Y.P.S. Bajaj (ed.). Biotechnology in Agriculture and Forestry. Vol. II. Springer-Verlag, Berlin.

Neidz, R.P., S.S. Smith, K.V. Dunbar, C.T. Stephens, and H.H. Murakishi. 1989. Factors affecting shoot regeneration from cotyledonary explants of Cucumis melo. Plant Cell Tiss. Org. Cult. 18:313-319.

Pozueta-Romero, J., Houlne, G., Canas, L., Schantz, R., and J. Chamarro. 2001. Enhanced regeneration of tomato and pepper seedling explants for Agrobacterium-mediated transformation. Plant Cell Tissue Organ Cult. 67:173-180.

Sokal, R.R. and Rohlf, F.J. 1981. Biometry, $2^{\text {nd }}$. edition. W.H. Freeman, New York.

Yadav, R.C., M.T. Salah, and R. Grumet. 1996. High frequency shoot regeneration from leaf explants of muskmelon. Plant Cell Tiss. Org. Cult. 45:207-214.

Wehner, T.C. and R.D. Locy. 1981. In vitro adventitious shoot and root formation of cultivars and lines of Cucumis sativus L. HortScience 16:759-760. 